\title{
Long noncoding RNAs in cancer: from function to translation
}

\author{
Anirban Sahu ${ }^{1,2^{*}}$, Udit Singhal ${ }^{1,3^{*}}$, Arul M. Chinnaiyan ${ }^{1,2,3,4,5}$
}

\begin{abstract}
${ }^{1}$ Michigan Center for Translational Pathology, University of Michigan, Ann Arbor, Michigan USA.

${ }^{2}$ Department of Pathology, University of Michigan, Ann Arbor, Michigan USA. ${ }^{3}$ Howard Hughes Medical Institute, University of Michigan, Ann Arbor, Michigan USA. ${ }^{4}$ Comprehensive Cancer Center, University of Michigan, Ann Arbor, Michigan USA. ${ }^{5}$ Department of Urology, University of Michigan, Ann Arbor, Michigan USA.

*These authors contributed equally.
\end{abstract}

Corresponding author:

Arul M. Chinnaiyan, M.D. Ph.D.

Investigator, Howard Hughes Medical Institute

Comprehensive Cancer Center

University of Michigan Medical School

1400 E. Medical Center Dr. 5316 CCGC 5940

Ann Arbor, Ml 48109-5940

arul@med.umich.edu 


\section{$1 \quad$ Abstract}

2 While our understanding of the molecular mechanisms underlying cancer has

3 significantly improved, most of our knowledge focuses on protein-coding genes that

4 make up a fraction of the genome. Recent studies have uncovered thousands of long

5 noncoding RNAs (IncRNAs) that populate the cancer genome. A subset of these

6 molecules shows striking cancer- and lineage-specific expression patterns, suggesting

7 they may be potential drivers of cancer biology and have utility as clinical biomarkers.

8 Here, we discuss emerging modalities of IncRNA biology and their interplay with cancer-

9 associated concepts, including epigenetic regulation, DNA damage and cell cycle

10 control, microRNA silencing, signal transduction pathways, and hormone-driven

11 disease. Additionally, we highlight the translational impact of IncRNAs, tools for their

12 mechanistic investigation, and directions for future IncRNA research. 


\section{The emergence of IncRNAs in cancer}

Cancer is a complex disease consisting of multiple factors that lead to the development of malignant tumors [1]. While much progress has been made in identifying the major contributors to cancer progression, the clinical picture remains bleak. Current research efforts aim to better understand the interplay between cancer cells, tumor microenvironments, and defense mechanisms involved in cancer development, immune evasion, and therapeutic susceptibility [1]. However, the majority of these studies focus on protein-coding genes as the crucial components in disease progression, overlooking the vast landscape of noncoding genes.

Among these noncoding transcripts are long noncoding RNAs (IncRNAs). LncRNAs are RNA species greater than 200 base pairs in length commonly characterized by polyadenylation, splicing of multiple exons, promoter trimethylation of histone $\mathrm{H} 3$ at lysine 4 (H3K4me3), and transcription by RNA polymerase II [2, 3]. LncRNA-mediated biology has been implicated in a wide variety of cellular processes, including pluripotency in mouse embryonic stem cells [4] and X chromosome inactivation [5]. While some IncRNAs, such as XIST, appear to operate exclusively in the nucleus as regulators of gene expression $[5,6]$, others function predominantly in the cytoplasm to regulate signal transduction and the stability of mRNAs [7-9]. Several distinct mechanisms of IncRNA activity have been described. Most prominently, IncRNAs have been shown to collaborate with protein partners to form ribonucleoprotein complexes [10] (see Glossary). For example, XIST interacts with the Polycomb repressive complex 2 (PRC2), resulting in PRC2 recruitment and subsequent trimethylation of histone $\mathrm{H} 3$ at 
4

lysine 27 (H3K27me3) of the inactive $\mathrm{X}$ chromosome [11]. Air and Kcnq1ot1 bind to G9a, a histone H3 lysine 9 methylase, to regulate gene expression [12, 13]. ANRIL associates with PRC1 to regulate the INK4a locus [14]. LincRNA-p21 and PANDA are two p53-regulated IncRNAs that interact with hnRNP-K and NF-YA to regulate transcription $[15,16]$. LncRNA-LET is downregulated across several cancers and functions by binding to and degrading nuclear factor 90 (NF90) protein, which enhances hypoxia-induced cancer cell invasion [17]. Given this tendency to engage proteins, IncRNAs are surfacing as decoys, scaffolds, and guides [18].

In cancer, IncRNAs are emerging as a prominent layer of previously underappreciated transcriptional regulation that function as both oncogenes and tumor suppressors [2] (Table 1). For example, overexpression of the HOTAIR IncRNA correlates with aggressive breast [19], colorectal [20], hepatocellular [21], and gastrointestinal stromal tumors [22], while IncRNA TARID prevents cancer formation through promoter demethylation at tumor suppressors [23]. In this review, we discuss emerging themes of IncRNA-mediated function within major areas of cancer progression and metastasis, focusing on advances made over the last several years (Fig. 1).

(1)

\section{Epigenetic regulation}

Cancer results from an accumulation of modified genes, either by mutation or epigenetic alterations such as methylation, acetylation, and phosphorylation [24]. Growing evidence suggests key cellular genes involved in proliferation, apoptosis, and stem cell 
differentiation are epigenetically modified in cancer [25]. However, the mechanisms underlying precise epigenetic control are poorly understood.

An evolving model of IncRNA activity centers on their ability to bind and regulate epigenetic complexes [26]. Specifically, several IncRNAs have been shown to function by interacting with Polycomb group complexes [18]. This is especially relevant in cancer, as PRC1 and 2 are known oncogenic drivers in several types of malignancies [27-30]. For example, FAL1 (Focally Amplified LncRNA on chromosome 1), a novel oncogenic IncRNA present across several epithelial tumors, associates with BMI1, a core subunit of the PRC1 complex [31]. In ovarian cancer, FAL1 was shown to mediate cancer progression and was associated with decreased patient survival. FAL1's interaction with BMl1 stabilizes the PRC1 complex by preventing BMl1 degradation, allowing PRC1 to occupy and repress promoters of target genes such as $p 21$, resulting in loss of cell cycle regulation and increased tumorigenesis.

Similarly, NBAT-1, IncRNA-HEIH, HOTAIR, ANRIL, TUG1, and XIST have all been shown to interact with the enzymatic subunit of the PRC2 complex, EZH2, to modulate the repressive H3K27me3 histone mark on downstream target genes. This subsequently leads to either oncogenesis or tumor suppression in a multitude of cancer types, including neuroblastoma [32], hepatocellular [33], breast [19], gastric [34], nonsmall cell lung carcinoma (NSCLC) [35], and hematologic malignancies [36], respectively. In fact, up to $20 \%$ of all IncRNAs have been implicated in PRC2 binding [37], suggesting that PRC2 promiscuously binds to IncRNAs [38]. Recent studies have 
shown both specific and non-specific binding of PRC2 to IncRNAs, and emerging evidence suggests that these activities are not mutually exclusive [39]. However, the in vivo binding specificity of PRC2 remains to be elucidated.

One of the most studied IncRNAs, HOTAIR (HOX transcript antisense RNA), recruits the PRC2 complex to a set of genes involved in suppressing breast cancer metastasis [19]. This genome-wide retargeting of PRC2 results in repression of genes that prevent cancer progression. Additionally, HOTAIR-mediated genetic reprogramming results in gene expression signatures that resemble embryonic fibroblast gene signatures, which promotes cell migration, invasion, and metastasis. LncRNAs can also interact with Polycomb group complexes indirectly. For example, PANDA (P21 Associated ncRNA DNA Damage Activated) physically interacts with scaffold-attachment-factor-A (SAFA) to indirectly recruit both the PRC1 and PRC2 complexes to the promoters of genes involved in cellular senescence [40]. This suggests that IncRNAs can facilitate epigenetic changes through interaction with protein intermediates.

In addition to Polycomb group complexes, several IncRNAs have been linked to the SWI/SNF nucleosome-remodeling complex in cancer and other diseases [41-44]. SWI/SNF is a multi-subunit complex that uses the energy of ATP hydrolysis to redistribute and rearrange nucleosomes to influence gene expression $[45,46]$. In cancer, SWI/SNF is widely considered a tumor-suppressor, as deleterious mutations are present in approximately $20 \%$ of all cancers [45, 47-49]. Indeed, SChLAP1 (Second Chromosome Locus Associated with Prostate-1), a prostate cancer-specific IncRNA that 
115 is highly expressed in $15-30 \%$ of localized and metastatic tumors [41], is significantly

associated with poor clinical outcomes and lethal disease. Moreover, SChLAP1

expression enhances tumor invasion and metastasis, in part, by interacting with and abrogating genome-wide binding of the SWI/SNF complex. Subsequent studies have defined SChLAP1 as one of the best prognostic genes in prostate cancer and have also shown the clinical utility of SChLAP1 as both a tissue- and urine-based biomarker [5052]. Comparably, IncTCF7 is highly expressed in hepatocellular carcinoma (HCC) and required for the maintenance of self-renewal capacity in liver cancer stem cells (CSC) [42]. Functionally, IncTCF7 triggers the Wnt signaling pathway by binding to and recruiting the SWI/SNF complex to the TCF7 promoter to activate gene expression. This preserves the self-renewal capabilities of liver CSCs and promotes tumor initiation in HCC. LncRNA-mediated SWI/SNF regulation has also been described in other cellular and disease processes. For example, Pol V-transcribed IncRNAs indirectly interact with the SWI/SNF complex to mediate transcriptional silencing [43]. Additionally, the cardioprotective IncRNA Mhrt directly interacts with BRG1, the catalytic subunit of SWI/SNF, to prevent cardiac hypertrophy [44]. Taken together, these studies suggest that IncRNAs play an important role in SWI/SNF regulation, and systematic efforts to characterize similar IncRNA mediators of SWI/SNF in other cancers warrants further investigation.

Additionally, HOTTIP (HOXA transcript at the distal tip) is another IncRNA upregulated in HCC [53]. HOTTIP expression is associated with clinical progression of HCC and is also an independent predictor of overall survival. Mechanistically, HOTTIP regulates the 
HOXA locus by interacting with the WDR5/MLL epigenetic complex to drive H3K4me3 [54]. Previous studies have identified an RNA binding pocket on WDR5 [55], suggesting that direct binding of IncRNAs to WDR5/MLL may similarly promote other cancers.

Epigenetic control by IncRNAs is not only exercised via interactions with chromatin remodelers. For example, TARID (TCF21 antisense RNA inducing demethylation) directs promoter demethylation of the tumor suppressive transcription factor TCF21 [23]. TARID is normally expressed in benign lung, oral, and ovarian epithelium but suppressed in cancer due to hypermethylation of its promoter. TARID acts as a scaffold to recruit GADD45A, a DNA demethylator, to the TCF21 promoter, resulting in demethylation of the TCF21 promoter through the base-excision repair pathway. The physical interaction between the TCF21 promoter, TARID, and GADD45A is critical for TCF21 expression and tumor suppression.

Insight into the biology and mechanism of IncRNAs provides a basis for the understanding of the global epigenetic modifications that occur in cancer.

\section{DNA damage and cell cycle regulation}

Proper responses to DNA damage and appropriate regulation of cell cycle checkpoints are essential for maintenance of cell integrity [56]. With alterations in more than $50 \%$ of all cancers, the p53 tumor suppressor mediates responses to DNA damage to prevent tumor-associated changes in cell metabolism, cell cycle checkpoint regulation and cell motility during cancer development [57]. While our current knowledge of these pathways 
161 is guiding targeted drug development in cancer [58], a thorough understanding of the

162 mechanisms governing p53-related function in early tumorigenesis remains elusive.

164 LncRNAs have surfaced as important regulators of p53 action and cell cycle regulation

165 in cancer. For example, lincRNA-p21 is regulated by p53 and serves as a repressor in

166 p53-dependent transcriptional responses by physically associating with and guiding

167 hnRNP-K to precise genomic targets [15]. Functionally, lincRNA-p21 is crucial to p53-

168 mediated apoptosis in response to DNA damage. LincRNA-p21 recruits hnRNP-K in cis

169 to promote p53-dependent transcription of p21, which is a well-known checkpoint

170 regulator in the p53 pathway [59]. The absence of lincRNA-p21 compromises the G1/S

171 checkpoint and results in increased proliferation.

172

173 Several IncRNAs are related to p53 regulation in response to cell stress, including

174 MEG3, TUG1, PANDA, and LED. The imprinted IncRNA MEG3 (Maternally Expressed

175 Gene 3) regulates cell proliferation and apoptosis by activating p53 in meningioma [60]

176 and NSCLC [61]. TUG1 [35] and PANDA [16] are directly regulated by p53 binding to

177 their promoters following DNA damage, and TUG1 and PANDA expression are reduced

178 in primary lung and breast tumors, respectively, compared to normal tissue.

179 Mechanistically, TUG1 recruits PRC2 to the promoter of HOXB7, reducing HOX-

180 mediated cell proliferation; PANDA binds to and abrogates chromatin binding of NF-YA,

181 leading to repression of apoptotic gene expression programs.

182 
183 Upon cellular stress, p53 also directly regulates enhancer RNAs (eRNAs), which

184 function by altering the expression of neighboring genes [62]. While many p53-induced

185 eRNAs have p53-binding sites, some do not, suggesting another mediator is involved in

186 regulating this subset of p53-responsive eRNAs. Recently, LED (LncRNA activator of

187 Enhancer Domains) was identified as a p53-induced IncRNA that associates with and

188 activates several of these remaining enhancers [63]. LED prominently associates with

189 the p21 enhancer and $L E D$ knockdown significantly influences G1 checkpoint arrest and

190 increases cell proliferation. Mechanistically, LED impacts eRNA production by

191 epigenetically increasing the deposition of the active enhancer histone mark, H3K9ac,

192 at specific loci. Interestingly, LED expression is downregulated by hypermethylation in

$19344 \%$ of cancer cell lines, suggesting $L E D$ is a p53-responsive IncRNA that regulates the

194 p53 transcriptional response and has tumor suppressive function.

195

196

Other IncRNAs play a vital role in mediating senescence and cell cycle arrest. The IncRNA MIR31HG is upregulated during oncogene-induced senescence (OIS) and antagonizes tumor suppressive function of P16 ${ }^{\text {INK4A }}$, resulting in decreased cell progression to S phase of the cell cycle [64]. MIR31HG functions by mediating Polycomb group protein-mediated repression of the INK4A locus. CARLo-5 (CancerAssociated Region Long non-coding RNA), a IncRNA implicated in colorectal cancer [65], prostate cancer [65], gastric cancer [66], and NSCLC [67], functions by blocking cell cycle arrest at the G1 phase, resulting in uninhibited cell proliferation. LncRNA gadd7 (Growth-Arrested DNA Damage-inducible gene 7) inhibits the G1/S cell cycle transition and its expression is induced in response to DNA-damaging agents, including 
UV irradiation, cisplatin, and growth arrest [68]. Prostate cancer-specific IncRNA PCAT1 (Prostate Cancer-Associated Transcript 1) is involved in the transcriptional repression of many genes related to mitosis and the cell cycle [69]. PCAT-1 expression is inversely correlated with BRCA2, and cells overexpressing PCAT-1 accumulate double-strand breaks (DSB) after treatment with DNA-damaging agents, suggesting its involvement in homologous recombination and DSB repair [70]. Downregulation of the tumorsuppressive IncRNA GAS5 (Growth Arrest-Specific 5) promotes cell proliferation, in part, by regulating cell cycle factors such as CDK6, E2F1, and p21 [71, 72].

Taken together, these mechanisms suggest that a subclass of IncRNAs are crucial gatekeepers of DNA damage repair, cell cycle progression, and apoptosis, and IncRNA dysregulation in this context contributes, in part, to cancer cell immortality.

\section{MicroRNA silencing}

MicroRNAs (miRNA) are small transcripts that have emerged as a prominent class of regulatory genes in numerous diseases, including cancer [73]. MiRNAs bind to complementary sequences on target RNAs, leading to repressed gene expression and blocked protein synthesis. Several IncRNAs mediate cancer progression by altering miRNA function. In the competing endogenous RNA (ceRNA) model, IncRNAs that harbor miRNA response elements can bind to and sequester miRNAs, preventing target transcript degradation $[9,74]$. While some experimental evidence has questioned the validity of the ceRNA hypothesis [75], many IncRNAs function via miRNA pathways, both directly and indirectly. 
230 The H19 IncRNA has been studied for decades as an important genetic factor in 231 development and cancer [76]. Two miRNA-based mechanisms have been described 232 regarding its function. First, $\mathrm{H} 19$ encodes for and produces miR-675 to promote gastric 233 cancer [77], colorectal cancer [78], and glioma [79]. Next, H19 modulates the let-7 234 family of miRNAs [80], which have vital roles in development, cancer, and metabolism miRNAs.

In HCC, HULC (Highly Upregulated in Liver Cancer) and IncRNA-ATB (Activated By sites for let-7 and acts as a miRNA sponge to sequester and regulate the let-7 family of

TGF- $\beta$ ) have been shown to function by miRNA-facilitated modalities. HULC, one of the most highly expressed IncRNAs in HCC, is a CREB (CAMP respone element binding protein)-regulated transcript that acts as a miRNA sponge to downregulate several miRNAs, including miR-372, leading to decreased translational repression of PRKACB and induced activation of CREB [82]. This results in an auto-regulatory loop in which HULC promotes its own expression. LncRNA-ATB enhances epithelial-mesenchymal transition(EMT), leading to cancer progression and tumor metastasis [83]. High IncRNAATB expression is correlated with decreased recurrence-free survival and overall survival in HCC patients. LncRNA-ATB interacts with several miR-200s, which have been previously shown to play a role in EMT suppression. Increased IncRNA-ATB expression results in decreased miR-200 level, suggesting that IncRNA-ATB functions as a microRNA sponge. Remarkably, in vivo xenograft studies showed that mutating 
252 miR-200 target sites on IncRNA-ATB decreased the abundance of circulating tumor

253 cells in mice [83].

255 In gastric cancer, GAPLINC (Gastric Adenocarcinoma Predictive Long Intergenic

256 Noncoding RNA) was identified as the most upregulated IncRNA in cancer compared to

257 normal tissue and correlates with poor patient outcomes [84]. Mechanistically,

258 GAPLINC regulates cell migration pathways by acting as a decoy for miR211-3p, a

259 miRNA implicated in CD44 oncogene degradation.

Moreover, IncRNAs can alter miRNA biology indirectly. The IncRNA ANRIL (Antisense Noncoding RNA in the INK4 Locus), which is known to function in tumor development and progression [85], is highly overexpressed in gastric cancer and correlates with worse disease prognosis [34]. ANRIL binds to PRC2 and is required for PRC2-mediated silencing of miR-99a and miR-449a. Downregulation of these miRNAs releases

266 inhibition of E2F1 and CDK6, allowing cell cycle progression and cell proliferation.

267 Subsequently, E2F1 reactivates ANRIL, forming a positive auto-regulatory loop.

Additionally, PCAT-1, one of the most differentially expressed IncRNAs in prostate cancer compared to benign tissues [69], promotes cell proliferation, in part, by 271 interfering with the regulation of $\mathrm{cMyc}$ by miR-34a [86]. Studies showed that PCAT-1 272 binds to MYC 3'-UTR, preventing miR-34a from engaging its target sequence. When 273 PCAT-1 was knocked down or a PCAT-1-specific miRNA was introduced into cells, 
274 CMYC stabilization was compromised, suggesting that PCAT-1 plays a crucial post-

275 transcriptional role in cMYC regulation.

276

277 These studies suggest that IncRNAs significantly influence miRNA biology by acting as

278 a precursor for miRNAs, directly binding to and sequestering miRNAs, or indirectly

279 interfering with miRNA expression and regulation. While the ceRNA hypothesis remains

280 controversial, it is clear that miRNAs are one of several avenues by which IncRNAs

281 mediate cancer progression and metastasis.

282

283 Signaling Pathways

284 The aberrant activation and propagation of cellular signals is a well-documented

285 phenomenon in cancer. LncRNAs that function in these signaling pathways are

286 becoming a major component of cancer mechanisms. As a key target of drug

287 development, further investigation in this area will potentially reveal therapeutic

288 vulnerabilities that can be targeted with novel compounds.

\section{Cellular signaling}

291 Several studies have highlighted the role of transforming growth factor- $\beta$ (TGF- $\beta$ ) [87],

292 Hedgehog [88], and Wnt [89] signaling pathways in tumor development. For example,

293 TGF- $\beta$ signaling promotes cancer cell metastasis in HCC via IncRNA-ATB. In addition to

294 regulating miRNAs, IncRNA-ATB is induced by TGF- $\beta$ and stabilizes IL-11 mRNA [83].

295 This allows increased IL-11 secretion and downstream IL-11/STAT3 signaling in an

296 autocrine fashion, leading to enhanced cell colonization at distant metastatic sites. 
298 In breast cancer, BCAR4 (Breast Cancer Anti-estrogen Resistance 4) was recently

299 identified as the most upregulated IncRNA expressed in stage III breast cancer versus

300 normal tissue, and increased expression was seen in later stage and metastatic

301 samples, correlating with shorter survival time in breast cancer patients [90]. In vitro and

302 in vivo experiments showed that BCAR4 increases breast cancer cell migration and

303 invasion through interactions with two transcription factors, leading to the activation of a

304 non-canonical Hedgehog signaling pathway. Additionally, overexpression of IncRNA

$305 \mathrm{H} 19$ due to aberrant Hedgehog signaling promotes osteosarcoma development in mice

306 [91].

307

308 The IncRNAs CCAT2 (Colon Cancer-Associated Transcript 2) and MALAT1

309 (Metastasis-Associated Lung Adenocarcinoma Transcript 1) drive tumor progression

310 and metastasis in breast [92], NSCLC [93], esophageal [94], colorectal [95], renal cell

311 [96], endometrial [97], and lung cancers [98] through general activation of the Wnt

312 signaling pathway. Moreover, IncTCF7 (described above) recruits the SWI/SNF

313 complex to promote Wnt signaling in HCC [42].

315 Additionally, some IncRNAs are involved in chemokine signaling. For example, BANCR

316 (BRAF-regulated IncRNA 1) is upregulated in cancer tissues with the active BRAF ${ }^{\mathrm{V} 600 \mathrm{E}}$

317 mutant and increases cell migration in melanoma through increased CXCL11

318 chemokine signaling [99]. BANCR also increases cell migration and invasion in NSCLC

319 by regulating E-cadherin, N-cadherin, and Vimentin, which play key roles in EMT [100]. 
These studies suggest that IncRNAs may promote tumorigenesis through varying mechanisms of signal transduction

\section{Hormonal regulation}

Several cancers are driven by hormone regulation [101]. In particular, estrogen and androgen steroid hormones stimulate breast and prostate cancers [102, 103]. Given the pivotal role of these hormone receptor pathways in propelling cancer progression, it comes as no surprise that IncRNAs are also involved in their function.

Prior to being described as a mediator of non-canonical Hedgehog signaling (described above), $B C A R 4$ was identified in a functional screen for genes involved in tamoxifen resistance [104]. Subsequent studies found that $B C A R 4$ expression is associated with shorter metastasis free survival and overall survival in breast cancer patients, and BCAR4 mediates estrogen-independent tumor growth [105]. In prostate cancer, NEAT1 (Nuclear Enriched Abundant Transcript 1), a IncRNA necessary for nuclear paraspeckle formation [106], was identified as an estrogen receptor alpha (ER-a)-regulated IncRNA with increased expression in prostate cancers compared to normal tissues [107]. NEAT1 coordinates prostate cancer oncogenesis by interacting at promoters of prostate-cancer associated genes. Importantly, prostate cancers expressing high levels of NEAT1 are unresponsive to androgen antagonists, suggesting that NEAT1 may play a role in metastatic castrate-resistant prostate cancers (mCRPC). Additionally, IncRNA GAS5 mediates apoptosis in hormone-driven prostate and breast cancers through binding steroid receptors [108]. 
344 The androgen receptor (AR) plays a central role in establishing an oncogenic cascade 345 that drives prostate cancer progression [109]. In fact, the mainstay of treatment for 346 prostate cancer involves androgen deprivation therapy (ADT) [110]. PCAT29 (Prostate

347 Cancer-Associated Transcript 29) [111] and DRAIC (Downregulated RNA In Cancer)

348 [112] are two androgen-suppressed IncRNAs located within 20kb of each other on 349 chromosome 15q23. Upon androgen stimulation, AR binds to the promoters of both 350 IncRNAs to repress their transcription. Lower PCAT29 and DRAIC expression 351 correlates with poor prognostic outcomes in prostate cancer patients. Tumors treated 352 with ADT showed higher levels of PCAT29, and tumors that progressed after ADT had 353 lower expression of $D R A I C$, suggesting that these IncRNAs may play a role in mediating 354 mCRPC. CTBP1-AS is another androgen-regulated IncRNA that mediates AR activity by directly 357 inhibiting the expression of the AR co-repressor CTBP1 [113]. CTBP1-AS functions by 358 recruiting histone deacetylases via the RNA-binding PTB-associated splicing factor 359 (PSF) to target gene promoters. CTBP1-AS knockdown suppresses androgen360 dependent cell proliferation in vitro and reduces xenograft tumor growth in vivo. 361 Furthermore, upregulation of CTBP1-AS and downregulation of CTBP1 is detected in 362 primary and metastatic prostate cancer samples, but not benign tissues, suggesting that 363 this IncRNA directly contributes to prostate cancer progression. 
Other IncRNAs have also been shown to directly mediate AR activity in prostate cancer. PRNCR1 and PCGEM1 are two IncRNAs that bind successively to AR to strongly enhance both ligand-dependent and ligand-independent AR-mediated gene activation and proliferation in prostate cancer cells [114]. However, the critical role of these IncRNAs in mCRPC remains questionable, as subsequent studies found extremely low levels of PRNCR1 expression in metastatic prostate tumors and lack of IncRNA binding to AR in prostate cells [115]. Nevertheless, PCGEM1 may play a role in mediating disease progression during early stages of prostate cancer [116], and further experimentation is necessary to delineate the precise role of these IncRNAs in mediating AR function.

\section{Downstream mediators}

The MYC proto-oncogene is a downstream effector of many signal transduction pathways and alterations in MYC are known to be oncogenic [117]. The human chromosomal 8q24 region includes a gene desert that contains enhancer elements that regulate MYC activity through long range chromatin looping. LncRNAs are also implicated in these processes. In prostate cancer, PCAT-1 mediates CMYC regulation [86] and PCGEM1 (Prostate Cancer Gene Expression marker 1) co-activates AR and cMYC to regulate tumor metabolism [118]. The colorectal cancer-specific IncRNA CCAT1-L mediates chromatin looping to allow the MYC promoter to interact with its enhancer elements [119]. LncRNA PVT1 is transcribed from the gene desert associated with MYC, and PVT1 expression is required for the oncogenic potential of MYC-driven human cancers [120]. Specifically, in $98 \%$ of $M Y C$-amplified human tumors, PVT1 
expression is also upregulated, and PVT1 knockdown abolishes the tumorigenicity of cancers with MYC amplification. However, PVT1 itself is not sufficient to cause tumor development without concurrent MYC upregulation, suggesting a synergistic effect exists between PVT1 and MYC in cancer development.

The transcription factor NF-KB is also highly upregulated in a variety of cancers and plays a role in tumor microenvironment inflammation, resulting in cancer development, metastasis, and invasion [121]. NKILA (NF-KB Interacting LncRNA) is upregulated by $\mathrm{NF}-\mathrm{kB}$ and binds to NF-KB//KB to form a stable complex, preventing degradation of IKB and subsequent NF-KB activation [122]. Low NKILA expression is correlated with cancer metastasis, advanced stage, higher grade, increased tumor size, and decreased patient survival, suggesting a clinically important function of NKILA in mediating inflammationstimulated breast cancer.

\section{Translational implications of IncRNAs}

LncRNAs are beginning to show translational utility as both biomarkers and therapeutic targets (Fig. 2 and Table 2). Dozens of IncRNAs show promise as diagnostic and prognostic markers across several types of cancers [123]. In general, IncRNAs show higher tissue- and disease-specific expression compared to protein-coding genes [124]. In cancer, IncRNAs show striking cancer- and lineage-specificity, suggesting these molecules may be powerful biomarkers in the clinical setting [125]. Additionally, IncRNAs can be measured in blood, urine, and tissue, justifying the development of non-invasive tests [2]. For example, HULC is not only associated with poor prognosis in 
411 pancreatic cancer [126], but it is also highly detectable in the plasma of patients with

412 HCC compared to healthy controls [127]. In prostate cancer, PCA3 has proven to be a

413 powerful diagnostic urine marker [128]. Similarly, initial data show SChLAP1 can be

414 detected in both tissue and urine of patients with more aggressive prostate cancer [50-

415 52]. In addition to its prognostic value in colorectal carcinoma [129], renal cell carcinoma

416 [130], and glioma [131], MALAT1 can be detected in patient serum and may serve as a

417 diagnostic marker in prostate cancer [132]. Furthermore, $A A 174084$ [133] and a set of

418 oral IncRNAs [134] are found in gastric juices and saliva, and may serve as potential

419 non-invasive biomarkers in gastric and oral squamous cell cancers, respectively.

Direct targeting of IncRNAs may be a viable therapeutic strategy in cancer. Antisense technology has gained considerable traction over the past few years as several antisense oligonucleotides (ASOs) have been introduced into clinical trials and some

424 have been FDA-approved for clinical use [135-138]. ASOs function by basepair hybridizing to target RNAs, resulting in transcript-specific RNAse $\mathrm{H}$-mediated catalytic degradation [139]. ASOs are a particularly attractive therapeutic modality for several reasons, including predictable human pharmacokinetics, prolonged tissue elimination 428 half-lives, enhanced specificity compared to small molecule inhibitors, and lack of cytochrome P450 enzyme metabolism [91, 139-141]. These characteristics are thought

430 to make ASOs safer for patients and also more suitable for combination therapies with

431 other drugs. Given the important role of IncRNAs across several cancer pathways, 432 ASO-mediated therapies are likely to surface as a promising class of new cancer drugs over the next few years. 


\section{Concluding Remarks}

436 While we attempted to classify IncRNAs by their predominant mechanistic modality, 437 most transcripts could fit into multiple categories, suggesting that IncRNAs may form 438 important regulatory networks that can coordinate numerous aspects of cancer 439 progression simultaneously. Although our understanding of IncRNA-mediated cancer 440 biology has increased significantly in the last several years, we believe this is only the 441 tip of the iceberg (Outstanding Questions Box). A continued understanding of the role of 442 IncRNAs in cancer will be enhanced by new tools that uncover novel IncRNAs, better 443 annotate known IncRNAs, as well as assess IncRNA localization, structure and function 444 (Text Box 1).

446 While new biological and computational techniques have greatly accelerated our ability 447 to investigate RNAs in cancer research, most IncRNA discovery and annotation efforts 448 in cancer have been severely limited, with poor overlap between different catalogues 449 [142], avoidance of monoexonic transcripts and complex regions of the genome [143], 450 poor bioinformatics tools for ab initio assembly of novel transcripts [144], and small 451 cohorts from which to reconstruct the cancer transcriptome [69]. Moreover, several 452 studies continue to rely on microarray-based platforms for the identification of disease453 associated IncRNAs [90, 145]; however, their use in discovering new IncRNAs is limited 454 because gene expression probes are designed against previously annotated transcripts.

455 Therefore, RNA-seq remains the most powerful tool to discover new IncRNAs in an 456 unbiased fashion [146, 147]. 
Additionally, almost all IncRNA studies to date have focused on the aberrant expression patterns of novel transcripts in cancer. While this is an essential first step to identify

460 important IncRNAs in cancer, future analyses will need to include transcript variants that 461 populate and drive cancer. Protein alterations such as point mutations, deletions and 462 amplifications, and gene fusions have emerged as key regulators in cancer [148, 149]. As our understanding of cancer-associated IncRNAs expands, similar variants will also 464 need to be explored in noncoding transcripts. Furthermore, studying isoform-specific 465 functions may reveal new insights on IncRNA gene function $[10,125]$. Uncovering the 466 precise function of IncRNAs in cell and animal models also cannot be overlooked. While 467 methods to knockdown (ASOs and Locked Nucleic Acids (LNAs) [150]) and knockout (CRISPR) [151, 152] IncRNA genes are improving, caution should be taken when employing these tools to explore IncRNA function [153].

Less than a decade ago, IncRNAs were mostly ignored, often considered "junk" DNA 472 and attributed to leaky transcription. Now, functional, mechanistic, and translational 473 insights have revealed the crucial role of IncRNAs in cell biology and disease 474 pathogenesis. Importantly, IncRNAs are emerging as critical players in cancer progression and metastasis. Given the tissue- and disease-specific nature of these 476 transcripts, their abundance throughout the genome, and the relatively recent discovery 477 of the majority of these transcripts, it is likely that IncRNAs hold the answer to questions 478 in cancer that have eluded us for years. 


\section{Acknowledgements}

We thank Robin Kunkel for assistance with figure preparation and Karen Giles for critically reading the manuscript and for the submission of documents. This work was supported in part by US National Institutes of Health Prostate Specialized Program of Research Excellence grant P50 CA69568, Early Detection Research Network grant UO1 CA111275, US National Institutes of Health grant R01 CA132874 (A.M.C.), and US Department of Defense grant PC100171 (A.M.C.). A.M.C. is supported by the Prostate Cancer Foundation and the Howard Hughes Medical Institute. A.M.C. is an American Cancer Society Research Professor and a Taubman Scholar of the University of Michigan. A.S. is supported by a Prostate Cancer Foundation Young Investigator Award and by a National Institutes of Health Ruth L. Kirschstein National Research Service Award F30 CA180376. A.S. is a Fellow of the University of Michigan Medical Scientist Training Program. U.S. is supported by the Howard Hughes Medical Institute Medical Research Fellows Program. A.M.C. serves on the scientific advisory board of Paradigm. He is a co-inventor on patents filed by the University of Michigan covering the diagnostic and therapeutic field of use for T2-ERG in prostate cancer which has been licensed to Hologic and the diagnostic and therapeutic field of use for SChLAP1 which has been co-licensed to Genome Dx. Paradigm, Hologic, and Genome Dx did not play roles in the design and conduct of this study, in the collection, analysis, or interpretation of the data, or in the preparation, review, or approval of the article. 


\section{Text Box 1. Tools for IncRNA investigation}

510 Several techniques and tools have been developed to discover and study IncRNAs (Fig. 3). RNA-seq has emerged as the most powerful method of IncRNA discovery. Recently,

512 a large-scale IncRNA annotation effort identified nearly 60,000 IncRNAs across the 513 cancer genome, suggesting that a large portion of the human transcriptome remains 514 unexplored [125]. The MiTranscriptome portal (www.mitranscriptome.org) was

515 developed using RNA-seq data from over 6,500 samples comprised of benign and 516 malignant tissues as well as cell lines, making it the most comprehensive IncRNA 517 annotation to date. Furthermore, a Sample Set Enrichment Analysis (SSEA) revealed approximately 8,000 previously unknown IncRNAs showing tissue- and/or cancer-

519 specificity, providing the scientific community with a vast database of potentially critical 520 molecules for future study. While this new resource will provide a foundation for IncRNA 521 genomics and cancer disease mechanisms, it is limited to poly-adenylated transcripts.

522 Future sequencing and annotation efforts will need to focus on also identifying non-poly523 adenylated IncRNAs. 
525 Novel methods to isolate RNA in vivo have led to the discovery of chromatin, RNA, and protein interacting partners of IncRNA transcripts. RNA pulldown methods such as chromatin isolation by RNA purification (ChIRP) [154] and RNA antisense purification (RAP) [155] have aided in the discovery of IncRNA function. These methods utilize antisense complementary oligonucleotides to isolate a target RNA and its associated molecules. Downstream sequencing and mass-spectrometry analysis can then be used to identify novel interactors in an unbiased manner.

Another useful tool to delineate IncRNA function is direct visualization. Single-molecule RNA-FISH (fluorescence in situ hybridization) is a powerful method to localize and visualize IncRNAs expression patterns in cells and tissues [156, 157]. Multiplexing RNAFISH with protein immunofluorescence can also be used to identify and confirm RNA-

537 protein interactions.

One of the greatest biological challenges has been the structural analysis of RNA 540 molecules in vivo. A new approach, termed icSHAPE (in vivo click selective 2'-hydroxyl 541 acylation and profiling experiment) enables RNA structure analysis in vivo at nucleotide 542 resolution for all four bases and can identify RNA strandedness [158]. Perhaps the most 543 relevant aspect of this technique to IncRNAs is the ability to differentiate structural 544 changes in RNA at protein-binding sites.

546 Traditionally, computational methods are used to determine whether RNA is coding or 547 noncoding. A variety of tools analyze sequence features such as open reading frame 
(ORF) length and the presence of a protein domain within a transcript. A subset of IncRNAs has been classified as TUCPs (Transcript of Unknown Coding Potential) [125, 143]. This is especially relevant as several examples of novel small peptides produced from putative IncRNAs have been described [159]. Improved bioinformatics tools and experimental methods, such as ribosomal profiling [160], should be employed to thoroughly assess the protein-coding capacity of a transcript.

\section{References}

1 Hanahan, D. and Weinberg, R.A. (2011) Hallmarks of cancer: the next generation. Cell 144, 646-674

2 Prensner, J.R. and Chinnaiyan, A.M. (2011) The emergence of IncRNAs in cancer biology. Cancer discovery 1, 391-407

3 Guttman, M., et al. (2009) Chromatin signature reveals over a thousand highly conserved large non-coding RNAs in mammals. Nature 458, 223-227

4 Guttman, M., et al. (2011) lincRNAs act in the circuitry controlling pluripotency and differentiation. Nature

5 Lee, J.T. (2009) Lessons from X-chromosome inactivation: long ncRNA as guides and tethers to the epigenome. Genes Dev 23, 1831-1842

6 Rinn, J.L., et al. (2007) Functional demarcation of active and silent chromatin domains in human HOX loci by noncoding RNAs. Cell 129, 1311-1323

7 Gong, C. and Maquat, L.E. (2011) IncRNAs transactivate STAU1-mediated mRNA decay by duplexing with 3' UTRs via Alu elements. Nature 470, 284-288

8 Poliseno, L., et al. (2010) A coding-independent function of gene and pseudogene mRNAs regulates tumour biology. Nature 465, 1033-1038

9 Salmena, L., et al. (2011) A ceRNA hypothesis: the Rosetta Stone of a hidden RNA language? Cell 146, 353-358

10 Rinn, J.L. and Chang, H.Y. (2012) Genome regulation by long noncoding RNAs. Annual review of biochemistry 81, 145-166

11 Zhao, J., et al. (2008) Polycomb proteins targeted by a short repeat RNA to the mouse $X$ chromosome. Science 322, 750-756

12 Nagano, T., et al. (2008) The Air noncoding RNA epigenetically silences transcription by targeting G9a to chromatin. Science 322, 1717-1720

13 Pandey, R.R., et al. (2008) Kcnq1 ot1 antisense noncoding RNA mediates lineagespecific transcriptional silencing through chromatin-level regulation. Molecular cell 32, 232-246

14 Yap, K.L., et al. (2010) Molecular interplay of the noncoding RNA ANRIL and methylated histone $\mathrm{H} 3$ lysine 27 by polycomb CBX7 in transcriptional silencing of INK4a. Molecular cell 38, 662-674 
15 Huarte, M., et al. (2010) A large intergenic noncoding RNA induced by p53 mediates global gene repression in the p53 response. Cell 142, 409-419 16 Hung, T., et al. (2011) Extensive and coordinated transcription of noncoding RNAs within cell-cycle promoters. Nature genetics 43, 621-629 17 Yang, F., et al. (2013) Repression of the long noncoding RNA-LET by histone deacetylase 3 contributes to hypoxia-mediated metastasis. Molecular cell 49, 10831096

18 Wang, K.C. and Chang, H.Y. (2011) Molecular mechanisms of long noncoding RNAs. Molecular cell 43, 904-914

19 Gupta, R.A., et al. (2010) Long non-coding RNA HOTAIR reprograms chromatin state to promote cancer metastasis. Nature 464, 1071-1076 20 Kogo, R., et al. (2011) Long noncoding RNA HOTAIR regulates polycombdependent chromatin modification and is associated with poor prognosis in colorectal cancers. Cancer Res 71, 6320-6326

21 Yang, Z., et al. (2011) Overexpression of long non-coding RNA HOTAIR predicts tumor recurrence in hepatocellular carcinoma patients following liver transplantation. Ann Surg Oncol 18, 1243-1250

22 Niinuma, T., et al. (2012) Upregulation of miR-196a and HOTAIR Drive Malignant Character in Gastrointestinal Stromal Tumors. Cancer Res 72, 1126-1136 23 Arab, K., et al. (2014) Long noncoding RNA TARID directs demethylation and activation of the tumor suppressor TCF21 via GADD45A. Molecular cell 55, 604-614 24 Sharma, S., et al. (2010) Epigenetics in cancer. Carcinogenesis 31, 27-36 25 Esteller, M. (2008) Epigenetics in cancer. The New England journal of medicine 358, 1148-1159

26 Lee, J.T. (2012) Epigenetic regulation by long noncoding RNAs. Science 338, 14351439

27 Kleer, C.G., et al. (2003) EZH2 is a marker of aggressive breast cancer and promotes neoplastic transformation of breast epithelial cells. Proceedings of the National Academy of Sciences of the United States of America 100, 11606-11611 28 Varambally, S., et al. (2002) The polycomb group protein EZH2 is involved in progression of prostate cancer. Nature 419, 624-629

29 Schwartz, Y.B. and Pirrotta, V. (2013) A new world of Polycombs: unexpected partnerships and emerging functions. Nature reviews. Genetics 14, 853-864 30 Margueron, R. and Reinberg, D. (2011) The Polycomb complex PRC2 and its mark in life. Nature 469, 343-349

$31 \mathrm{Hu}, \mathrm{X}$., et al. (2014) A functional genomic approach identifies FAL1 as an oncogenic long noncoding RNA that associates with BMl1 and represses p21 expression in cancer. Cancer cell 26, 344-357

32 Pandey, G.K., et al. (2014) The risk-associated long noncoding RNA NBAT-1 controls neuroblastoma progression by regulating cell proliferation and neuronal differentiation. Cancer cell 26, 722-737

33 Yang, F., et al. (2011) Long noncoding RNA high expression in hepatocellular carcinoma facilitates tumor growth through enhancer of zeste homolog 2 in humans. Hepatology 54, 1679-1689 
662

663

664

665

666

667

668

669

670

671

672

673

674

675

34 Zhang, E.B., et al. (2014) Long noncoding RNA ANRIL indicates a poor prognosis of gastric cancer and promotes tumor growth by epigenetically silencing of miR-99a/miR449a. Oncotarget 5, 2276-2292

35 Zhang, E.B., et al. (2014) P53-regulated long non-coding RNA TUG1 affects cell proliferation in human non-small cell lung cancer, partly through epigenetically regulating HOXB7 expression. Cell death \& disease 5, e1243

36 Yildirim, E., et al. (2013) Xist RNA is a potent suppressor of hematologic cancer in mice. Cell 152, 727-742

37 Khalil, A.M., et al. (2009) Many human large intergenic noncoding RNAs associate with chromatin-modifying complexes and affect gene expression. Proceedings of the National Academy of Sciences of the United States of America 106, 11667-11672 38 Davidovich, C., et al. (2013) Promiscuous RNA binding by Polycomb repressive complex 2. Nature structural \& molecular biology 20, 1250-1257

39 Davidovich, C., et al. (2015) Toward a consensus on the binding specificity and promiscuity of PRC2 for RNA. Molecular cell 57, 552-558

40 Puvvula, P.K., et al. (2014) Long noncoding RNA PANDA and scaffold-attachmentfactor SAFA control senescence entry and exit. Nature communications 5, 5323 41 Prensner, J.R., et al. (2013) The long noncoding RNA SChLAP1 promotes aggressive prostate cancer and antagonizes the SWI/SNF complex. Nature genetics 45 , 1392-1398

42 Wang, Y., et al. (2015) The Long Noncoding RNA IncTCF7 Promotes Self-Renewal of Human Liver Cancer Stem Cells through Activation of Wnt Signaling. Cell stem cell 16, 413-425

$43 \mathrm{Zhu}, \mathrm{Y}$., et al. (2013) A SWI/SNF chromatin-remodeling complex acts in noncoding RNA-mediated transcriptional silencing. Molecular cell 49, 298-309

$44 \mathrm{Han}, \mathrm{P}$., et al. (2014) A long noncoding RNA protects the heart from pathological hypertrophy. Nature 514, 102-106

45 Wilson, B.G. and Roberts, C.W. (2011) SWI/SNF nucleosome remodellers and cancer. Nature reviews. Cancer 11, 481-492

46 Lu, P. and Roberts, C.W. (2013) The SWI/SNF tumor suppressor complex:

Regulation of promoter nucleosomes and beyond. Nucleus 4, 374-378

47 Reisman, D., et al. (2009) The SWI/SNF complex and cancer. Oncogene 28, 16531668

48 Shain, A.H. and Pollack, J.R. (2013) The spectrum of SWI/SNF mutations, ubiquitous in human cancers. PloS one 8, e55119

49 Kadoch, C., et al. (2013) Proteomic and bioinformatic analysis of mammalian $\mathrm{SWI} / \mathrm{SNF}$ complexes identifies extensive roles in human malignancy. Nature genetics $45,592-601$

50 Prensner, J.R., et al. (2014) RNA biomarkers associated with metastatic progression in prostate cancer: a multi-institutional high-throughput analysis of SChLAP1. Lancet Oncol 15, 1469-1480

51 Mehra, R., et al. (2014) A novel RNA in situ hybridization assay for the long noncoding RNA SChLAP1 predicts poor clinical outcome after radical prostatectomy in clinically localized prostate cancer. Neoplasia 16, 1121-1127 52 Bottcher, R., et al. (2015) Novel long non-coding RNAs are specific diagnostic and prognostic markers for prostate cancer. Oncotarget 
53 Quagliata, L., et al. (2014) Long noncoding RNA HOTTIP/HOXA13 expression is associated with disease progression and predicts outcome in hepatocellular carcinoma patients. Hepatology 59, 911-923

54 Wang, K.C., et al. (2011) A long noncoding RNA maintains active chromatin to coordinate homeotic gene expression. Nature 472, 120-124

55 Yang, Y.W., et al. (2014) Essential role of IncRNA binding for WDR5 maintenance of active chromatin and embryonic stem cell pluripotency. eLife 3, e02046

56 Zhou, B.B. and Elledge, S.J. (2000) The DNA damage response: putting checkpoints in perspective. Nature 408, 433-439

57 Muller, P.A. and Vousden, K.H. (2013) p53 mutations in cancer. Nature cell biology $15,2-8$

58 Vazquez, A., et al. (2008) The genetics of the p53 pathway, apoptosis and cancer therapy. Nature reviews. Drug discovery 7, 979-987

59 Dimitrova, N., et al. (2014) LincRNA-p21 activates p21 in cis to promote Polycomb target gene expression and to enforce the G1/S checkpoint. Molecular cell 54, 777-790 60 Zhang, X., et al. (2010) Maternally expressed gene 3, an imprinted noncoding RNA gene, is associated with meningioma pathogenesis and progression. Cancer research 70, 2350-2358

$61 \mathrm{Lu}, \mathrm{K} . \mathrm{H}$., et al. (2013) Long non-coding RNA MEG3 inhibits NSCLC cells proliferation and induces apoptosis by affecting p53 expression. BMC cancer 13, 461 62 Younger, S.T., et al. (2015) Integrative genomic analysis reveals widespread enhancer regulation by $\mathrm{p} 53$ in response to DNA damage. Nucleic acids research 63 Leveille, N., et al. (2015) Genome-wide profiling of p53-regulated enhancer RNAs uncovers a subset of enhancers controlled by a IncRNA. Nature communications 6 , 6520

64 Montes, M., et al. (2015) The IncRNA MIR31HG regulates p16(INK4A) expression to modulate senescence. Nature communications 6, 6967

$65 \mathrm{Kim}$, T., et al. (2014) Long-range interaction and correlation between MYC enhancer and oncogenic long noncoding RNA CARLo-5. Proceedings of the National Academy of Sciences of the United States of America 111, 4173-4178 66 Zhang, Y., et al. (2014) Enhanced expression of long noncoding RNA CARLo-5 is associated with the development of gastric cancer. International journal of clinical and experimental pathology $7,8471-8479$

67 Luo, J., et al. (2014) Long non-coding RNA CARLo-5 is a negative prognostic factor and exhibits tumor pro-oncogenic activity in non-small cell lung cancer. Tumour biology : the journal of the International Society for Oncodevelopmental Biology and Medicine $35,11541-11549$

68 Liu, X., et al. (2012) Long non-coding RNA gadd7 interacts with TDP-43 and regulates Cdk6 mRNA decay. The EMBO journal 31, 4415-4427

69 Prensner, J.R., et al. (2011) Transcriptome sequencing across a prostate cancer cohort identifies PCAT-1, an unannotated lincRNA implicated in disease progression. Nature biotechnology 29, 742-749 70 Prensner, J.R., et al. (2014) PCAT-1, a long noncoding RNA, regulates BRCA2 and controls homologous recombination in cancer. Cancer research 74, 1651-1660 $71 \mathrm{Liu}, \mathrm{Z}$., et al. (2013) Downregulation of GAS5 promotes bladder cancer cell proliferation, partly by regulating CDK6. PloS one 8, e73991 
72 Sun, M., et al. (2014) Decreased expression of long noncoding RNA GAS5 indicates a poor prognosis and promotes cell proliferation in gastric cancer. BMC cancer 14, 319 73 lorio, M.V. and Croce, C.M. (2012) MicroRNA dysregulation in cancer: diagnostics, monitoring and therapeutics. A comprehensive review. EMBO molecular medicine 4, 143-159

74 Tay, Y., et al. (2014) The multilayered complexity of ceRNA crosstalk and competition. Nature 505, 344-352

75 Denzler, R., et al. (2014) Assessing the ceRNA hypothesis with quantitative measurements of miRNA and target abundance. Molecular cell 54, 766-776 76 Cui, H., et al. (2002) Loss of imprinting in colorectal cancer linked to hypomethylation of H19 and IGF2. Cancer research 62, 6442-6446 77 Zhuang, M., et al. (2014) The long non-coding RNA H19-derived miR-675 modulates human gastric cancer cell proliferation by targeting tumor suppressor RUNX1. Biochemical and biophysical research communications 448, 315-322

78 Tsang, W.P., et al. (2010) Oncofetal H19-derived miR-675 regulates tumor suppressor RB in human colorectal cancer. Carcinogenesis 31, 350-358 79 Shi, Y., et al. (2014) Long non-coding RNA H19 promotes glioma cell invasion by deriving miR-675. PloS one 9, e86295 80 Kallen, A.N., et al. (2013) The imprinted H19 IncRNA antagonizes let-7 microRNAs. Molecular cell 52, 101-112

81 Roush, S. and Slack, F.J. (2008) The let-7 family of microRNAs. Trends in cell biology 18, 505-516

82 Wang, J., et al. (2010) CREB up-regulates long non-coding RNA, HULC expression through interaction with microRNA-372 in liver cancer. Nucleic acids research 38, 53665383

83 Yuan, J.H., et al. (2014) A long noncoding RNA activated by TGF-beta promotes the invasion-metastasis cascade in hepatocellular carcinoma. Cancer cell 25, 666-681 $84 \mathrm{Hu}$, Y., et al. (2014) Long noncoding RNA GAPLINC regulates CD44-dependent cell invasiveness and associates with poor prognosis of gastric cancer. Cancer research 74, 6890-6902

85 Pasmant, E., et al. (2007) Characterization of a germ-line deletion, including the entire INK4/ARF locus, in a melanoma-neural system tumor family: identification of ANRIL, an antisense noncoding RNA whose expression coclusters with ARF. Cancer research 67, 3963-3969

86 Prensner, J.R., et al. (2014) The long non-coding RNA PCAT-1 promotes prostate cancer cell proliferation through cMyc. Neoplasia 16, 900-908 87 Massague, J. (2008) TGFbeta in Cancer. Cell 134, 215-230 88 Taipale, J. and Beachy, P.A. (2001) The Hedgehog and Wnt signalling pathways in cancer. Nature 411, 349-354 89 Clevers, H. (2006) Wnt/beta-catenin signaling in development and disease. Cell 127, 469-480

90 Xing, Z., et al. (2014) IncRNA directs cooperative epigenetic regulation downstream of chemokine signals. Cell 159, 1110-1125

91 Chan, L.H., et al. (2014) Hedgehog signaling induces osteosarcoma development through Yap1 and H19 overexpression. Oncogene 33, 4857-4866 
92 Redis, R.S., et al. (2013) CCAT2, a novel long non-coding RNA in breast cancer: expression study and clinical correlations. Oncotarget 4, 1748-1762 93 Qiu, M., et al. (2014) CCAT2 is a lung adenocarcinoma-specific long non-coding RNA and promotes invasion of non-small cell lung cancer. Tumour biology : the journal of the International Society for Oncodevelopmental Biology and Medicine 35, 5375-5380 94 Wang, J., et al. (2015) Long noncoding RNA CCAT2 correlates with smoking in esophageal squamous cell carcinoma. Tumour biology : the journal of the International Society for Oncodevelopmental Biology and Medicine 95 Ling, H., et al. (2013) CCAT2, a novel noncoding RNA mapping to 8q24, underlies metastatic progression and chromosomal instability in colon cancer. Genome research 23, 1446-1461

96 Hirata, H., et al. (2015) Long Noncoding RNA MALAT1 Promotes Aggressive Renal Cell Carcinoma through Ezh2 and Interacts with miR-205. Cancer research 75, 13221331

97 Zhao, Y., et al. (2014) A novel wnt regulatory axis in endometrioid endometrial cancer. Cancer research 74, 5103-5117 98 Gutschner, T., et al. (2013) The noncoding RNA MALAT1 is a critical regulator of the metastasis phenotype of lung cancer cells. Cancer research 73, 1180-1189 99 Flockhart, R.J., et al. (2012) BRAFV600E remodels the melanocyte transcriptome and induces BANCR to regulate melanoma cell migration. Genome research 22, 10061014

100 Sun, M., et al. (2014) Downregulation of BRAF activated non-coding RNA is associated with poor prognosis for non-small cell lung cancer and promotes metastasis by affecting epithelial-mesenchymal transition. Molecular cancer 13, 68 101 Heinlein, C.A. and Chang, C. (2004) Androgen receptor in prostate cancer. Endocrine reviews 25, 276-308 102 Clemons, M. and Goss, P. (2001) Estrogen and the risk of breast cancer. The New England journal of medicine 344, 276-285

103 Scher, H.I. and Sawyers, C.L. (2005) Biology of progressive, castration-resistant prostate cancer: directed therapies targeting the androgen-receptor signaling axis. Journal of clinical oncology : official journal of the American Society of Clinical Oncology 23, 8253-8261

104 Meijer, D., et al. (2006) Functional screen for genes responsible for tamoxifen resistance in human breast cancer cells. Molecular cancer research : MCR 4, 379-386 105 Godinho, M., et al. (2011) Characterization of BCAR4, a novel oncogene causing endocrine resistance in human breast cancer cells. Journal of cellular physiology 226 , 1741-1749 106 Clemson, C.M., et al. (2009) An architectural role for a nuclear noncoding RNA: NEAT1 RNA is essential for the structure of paraspeckles. Molecular cell 33, 717-726 107 Chakravarty, D., et al. (2014) The oestrogen receptor alpha-regulated IncRNA NEAT1 is a critical modulator of prostate cancer. Nature communications 5, 5383 108 Hudson, W.H., et al. (2014) Conserved sequence-specific lincRNA-steroid receptor interactions drive transcriptional repression and direct cell fate. Nature communications 5,5395 109 Visakorpi, T., et al. (1995) In vivo amplification of the androgen receptor gene and progression of human prostate cancer. Nature genetics 9, 401-406 
110 Sharifi, N., et al. (2005) Androgen deprivation therapy for prostate cancer. Jama 294, 238-244

111 Malik, R., et al. (2014) The IncRNA PCAT29 inhibits oncogenic phenotypes in prostate cancer. Molecular cancer research : MCR 12, 1081-1087

112 Sakurai, K., et al. (2015) The IncRNA DRAIC/PCAT29 Locus Constitutes a TumorSuppressive Nexus. Molecular cancer research : MCR

113 Takayama, K., et al. (2013) Androgen-responsive long noncoding RNA CTBP1-AS promotes prostate cancer. The EMBO journal 32, 1665-1680

114 Yang, L., et al. (2013) IncRNA-dependent mechanisms of androgen-receptorregulated gene activation programs. Nature 500, 598-602

115 Prensner, J.R., et al. (2014) The IncRNAs PCGEM1 and PRNCR1 are not implicated in castration resistant prostate cancer. Oncotarget 5, 1434-1438 116 Parolia, A., et al. (2015) The long non-coding RNA PCGEM1 is regulated by androgen receptor activity in vivo. Molecular cancer 14, 46

117 Dang, C.V. (2012) MYC on the path to cancer. Cell 149, 22-35 118 Hung, C.L., et al. (2014) A long noncoding RNA connects C-Myc to tumor metabolism. Proceedings of the National Academy of Sciences of the United States of America 111, 18697-18702

119 Xiang, J.F., et al. (2014) Human colorectal cancer-specific CCAT1-L IncRNA regulates long-range chromatin interactions at the MYC locus. Cell research 24, 513531

120 Tseng, Y.Y., et al. (2014) PVT1 dependence in cancer with MYC copy-number increase. Nature 512, 82-86

121 Dolcet, X., et al. (2005) NF-kB in development and progression of human cancer. Virchows Archiv : an international journal of pathology 446, 475-482 122 Liu, B., et al. (2015) A cytoplasmic NF-kappaB interacting long noncoding RNA blocks IkappaB phosphorylation and suppresses breast cancer metastasis. Cancer cell 27, 370-381

$123 \mathrm{Qi}, \mathrm{P}$. and Du, X. (2013) The long non-coding RNAs, a new cancer diagnostic and therapeutic gold mine. Modern pathology : an official journal of the United States and Canadian Academy of Pathology, Inc 26, 155-165

124 Esteller, M. (2011) Non-coding RNAs in human disease. Nature reviews. Genetics $12,861-874$

125 lyer, M.K., et al. (2015) The landscape of long noncoding RNAs in the human transcriptome. Nature genetics 47, 199-208

126 Peng, W., et al. (2014) Long noncoding RNA HULC is a novel biomarker of poor prognosis in patients with pancreatic cancer. Medical oncology 31, 346

$127 \mathrm{Xie}, \mathrm{H}$., et al. (2013) Plasma HULC as a promising novel biomarker for the detection of hepatocellular carcinoma. BioMed research international 2013, 136106 128 Hessels, D., et al. (2003) DD3(PCA3)-based molecular urine analysis for the diagnosis of prostate cancer. European urology 44, 8-15; discussion 15-16 129 Zheng, H.T., et al. (2014) High expression of IncRNA MALAT1 suggests a biomarker of poor prognosis in colorectal cancer. International journal of clinical and experimental pathology $7,3174-3181$ 130 Zhang, H.M., et al. (2015) Upregulation of long non-coding RNA MALAT1 correlates with tumor progression and poor prognosis in clear cell renal cell carcinoma. 
Tumour biology : the journal of the International Society for Oncodevelopmental Biology and Medicine 36, 2947-2955

$131 \mathrm{Ma}, \mathrm{K} . \mathrm{X}$., et al. (2015) Long noncoding RNA MALAT1 associates with the malignant status and poor prognosis in glioma. Tumour biology : the journal of the International Society for Oncodevelopmental Biology and Medicine 36, 3355-3359

132 Ren, S., et al. (2013) Long non-coding RNA metastasis associated in lung adenocarcinoma transcript 1 derived miniRNA as a novel plasma-based biomarker for diagnosing prostate cancer. European journal of cancer 49, 2949-2959 133 Shao, Y., et al. (2014) Gastric juice long noncoding RNA used as a tumor marker for screening gastric cancer. Cancer 120, 3320-3328

134 Tang, H., et al. (2013) Salivary IncRNA as a potential marker for oral squamous cell carcinoma diagnosis. Molecular medicine reports 7, 761-766

135 Meng, L., et al. (2015) Towards a therapy for Angelman syndrome by targeting a long non-coding RNA. Nature 518, 409-412

136 Buller, H.R., et al. (2015) Factor XI antisense oligonucleotide for prevention of venous thrombosis. The New England journal of medicine 372, 232-240 137 Noveck, R., et al. (2014) Effects of an antisense oligonucleotide inhibitor of Creactive protein synthesis on the endotoxin challenge response in healthy human male volunteers. Journal of the American Heart Association 3

138 Gaudet, D., et al. (2014) Targeting APOC3 in the familial chylomicronemia syndrome. The New England journal of medicine 371, 2200-2206 139 Bennett, C.F. and Swayze, E.E. (2010) RNA targeting therapeutics: molecular mechanisms of antisense oligonucleotides as a therapeutic platform. Annual review of pharmacology and toxicology 50, 259-293

140 Fey, R.A., et al. (2014) Local and systemic tolerability of a 2'O-methoxyethyl antisense oligonucleotide targeting interleukin-4 receptor-alpha delivery by inhalation in mouse and monkey. Inhalation toxicology 26, 452-463

141 Geary, R.S., et al. (2015) Pharmacokinetics, biodistribution and cell uptake of antisense oligonucleotides. Advanced drug delivery reviews

142 Harrow, J., et al. (2012) GENCODE: the reference human genome annotation for The ENCODE Project. Genome Res 22, 1760-1774

143 Cabili, M.N., et al. (2011) Integrative annotation of human large intergenic noncoding RNAs reveals global properties and specific subclasses. Genes \& development 25, 1915-1927

144 Steijger, T., et al. (2013) Assessment of transcript reconstruction methods for RNAseq. Nature methods 10, 1177-1184

$145 \mathrm{Du}, \mathrm{Z}$., et al. (2013) Integrative genomic analyses reveal clinically relevant long noncoding RNAs in human cancer. Nature structural \& molecular biology 20, 908-913 146 Djebali, S., et al. (2012) Landscape of transcription in human cells. Nature 489, 101-108

147 Trapnell, C., et al. (2013) Differential analysis of gene regulation at transcript resolution with RNA-seq. Nature biotechnology 31, 46-53

148 Leary, R.J., et al. (2008) Integrated analysis of homozygous deletions, focal amplifications, and sequence alterations in breast and colorectal cancers. Proceedings of the National Academy of Sciences of the United States of America 105, 16224-16229 
149 Grasso, C.S., et al. (2012) The mutational landscape of lethal castration-resistant prostate cancer. Nature 487, 239-243 150 Wahlestedt, C., et al. (2000) Potent and nontoxic antisense oligonucleotides containing locked nucleic acids. Proceedings of the National Academy of Sciences of the United States of America 97, 5633-5638

$151 \mathrm{Gaj}$, T., et al. (2013) ZFN, TALEN, and CRISPR/Cas-based methods for genome engineering. Trends in biotechnology 31, 397-405

$152 \mathrm{Hsu}$, P.D., et al. (2014) Development and applications of CRISPR-Cas9 for genome engineering. Cell 157, 1262-1278

153 Bassett, A.R., et al. (2014) Considerations when investigating IncRNA function in vivo. elife 3, e03058

$154 \mathrm{Chu}, \mathrm{C}$., et al. (2011) Genomic maps of long noncoding RNA occupancy reveal principles of RNA-chromatin interactions. Molecular cell 44, 667-678 155 Engreitz, J.M., et al. (2014) RNA-RNA interactions enable specific targeting of noncoding RNAs to nascent Pre-mRNAs and chromatin sites. Cell 159, 188-199 156 Batish, M., et al. (2011) Single molecule imaging of RNA in situ. Methods in molecular biology 714, 3-13

157 Femino, A.M., et al. (1998) Visualization of single RNA transcripts in situ. Science 280, 585-590

158 Spitale, R.C., et al. (2015) Structural imprints in vivo decode RNA regulatory mechanisms. Nature 519, 486-490

159 Andrews, S.J. and Rothnagel, J.A. (2014) Emerging evidence for functional peptides encoded by short open reading frames. Nature reviews. Genetics 15, 193-204 160 Ingolia, N.T., et al. (2014) Ribosome profiling reveals pervasive translation outside of annotated protein-coding genes. Cell reports 8, 1365-1379 


\section{Figure Legends}

949 Figure 1: LncRNAs play a crucial role within major areas of cancer progression 950 and metastasis.

951 Long noncoding RNA (IncRNAs) mediate several cancer-associated processes, 952 including epigenetic regulation, DNA damage and cell cycle control, microRNA (miRNA) 953 silencing, signal transduction pathways, and hormone-driven disease. Figure 2: Translational implications of IncRNAs.

956 Long noncoding RNAs (IncRNAs) are emerging as both diagnostic and prognostic 957 biomarkers that can be detected in tissue, serum, and urine. Antisense oligonucleotides 958 (ASOs) can be used to directly target IncRNAs and are a promising therapeutic strategy 959 in cancer.

960

961 Figure 3: Tools for IncRNA investigation. 
962 Emerging areas for investigation in the long noncoding RNA (IncRNA) field include 963 improved discovery methods, unbiased interactome analysis, transcript visualization 964 and localization, RNA structure determination, discovery of small peptides produced 965 from short open reading frames (sORF), and identification and comprehension of 966 IncRNA variants.

967 


\section{Glossary}

Ribonucleoprotein complex (RNP): a cellular complex containing RNAs and proteins.

Polycomb Repressive Complex 2 (PRC2): a multi-protein complex containing the core components of SUZ12, EED, RbAp48 and EZH2. PRC2 primarily functions as a histone methyltransferase, adding a trimethyl group to histone H3 on lysine 27 (H3K27me3) to produce transcriptionally silent chromatin.

Epigenetics: the heritable variations in gene expression that result due to differences in how DNA is read rather than in the DNA sequence itself. Epigenetic alterations include DNA methylation and histone modifications.

Chromatin remodeler: a protein complex that physically changes DNA architecture to allow or restrict access of regulatory proteins and transcription machinery to DNA. The function of chromatin remodelers is often carried out by epigenetic modifications using the energy of ATP hydrolysis.

Enhancer RNA (eRNA): a class of non-coding RNAs that plays a role in enhancer DNAmediated transcriptional regulation. eRNAs have been shown to recruit RNA polymerase II to these DNA regions to assist in the initiation of gene transcription.

Oncogene induced senescence (OIS): a sustained induction of the Rb and p53 tumor suppressive pathways in response to an activating mutation in an oncogene or loss of tumor suppressive activity within a cell. The mechanism by which OIS occurs has not been fully elucidated, however it is known to protect against the progression to cancer in response to oncogenic stress.

Epithelial-mesenchymal transition (EMT): the cellular mechanism by which epithelial cells gain migratory and invasive properties to form mesenchymal cells. This phenomenon is often seen when cancer cells gain the ability to invade and metastasize to distant organs. EMT can also occur in normal biological processes, such as wound healing.

Transforming growth factor-beta signaling pathway (TGF- $\boldsymbol{\beta}$ ): a cellular signaling pathway involved in numerous physiological processes, including cell differentiation, cell growth, and apoptosis. Ligand binding initiates a cascade of signaling through serine/threonine receptor kinase activity.

Hedgehog signaling pathway: a cellular signaling pathway that is required for the regulation of embryonic cell development. Aberrations in Hedgehog signaling may result in developmental or growth defects.

Wnt signaling pathway: a cellular signaling pathway initiated by binding of Wnt ligand to a Frizzled family receptor, resulting in transmission of this signal to Dishevelled within the cell. This leads to downstream regulation of genes involved in embryonic development, cell differentiation, cell migration, and cell proliferation. 


\section{Outstanding Questions Box}

- How do IncRNA variants contribute to cancer progression?

- Differential expression patterns in cancer have guided IncRNA discovery and investigation thus far. LncRNA transcript variants such as mutations, amplifications, deletions, and fusions remain unexplored.

- How do IncRNAs coordinate various molecular networks to drive cancer?

- The majority of IncRNA studies to date have focused on a single mechanism of action. However, several transcripts have numerous functions, suggesting that IncRNAs may form important regulatory networks that can coordinate many aspects of cancer progression simultaneously.

- Do a subset of IncRNAs have protein-coding potential?

- Some IncRNAs have been identified as TUCPs (Transcripts of Unknown Coding Potential). Previously undiscovered small peptides produced from these IncRNAs may have significant roles in cancer biology.

- How can IncRNAs be used to guide precision medicine approaches in cancer?

- An emerging area of cancer therapeutics utilizes genomic signatures to guide treatment choices for patients. Current efforts employ aberrations in protein-coding genes; incorporating IncRNAs into these analyses may improve therapeutic response and patient outcomes.

- How can IncRNAs be utilized in the clinical setting?

- LncRNAs have been identified as powerful diagnostic and prognostic biomarkers. Targeting IncRNAs directly with antisense oligonucleotides may also be a promising therapeutic strategy. 


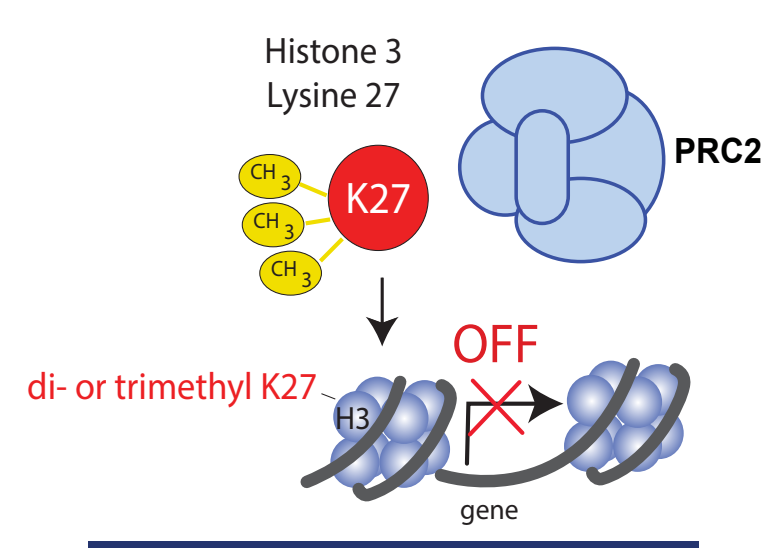

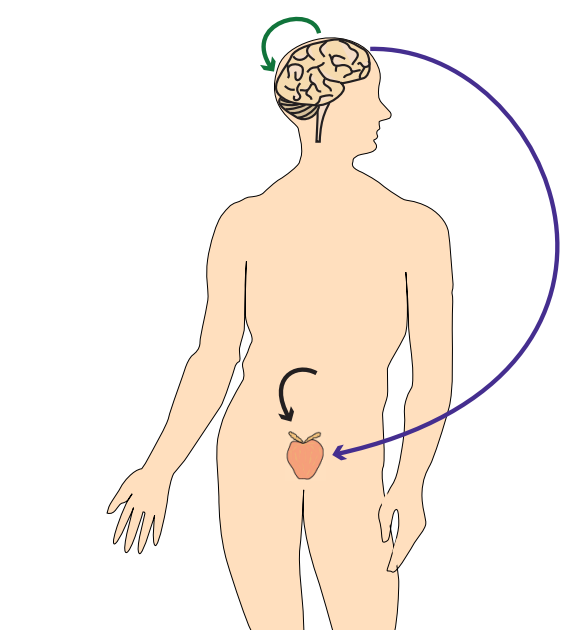

Hormone-driven Disease

\section{Signal Transduction Pathways}

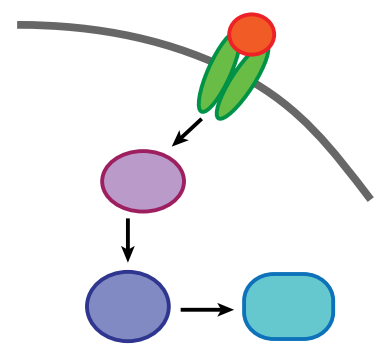

\section{Epigenetic Regulation}

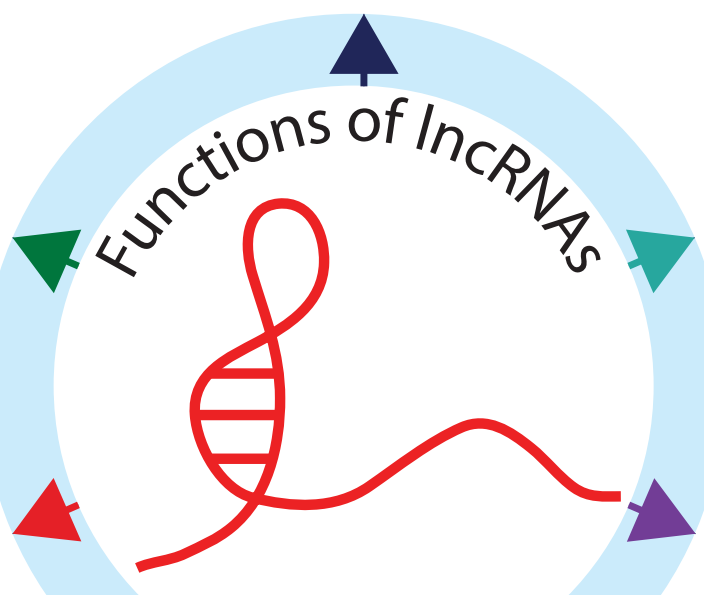

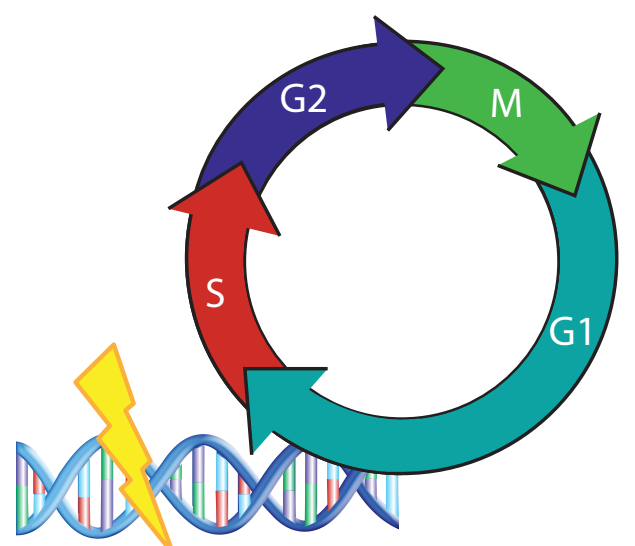

DNA Damage and Cell Cycle Control

\section{MicroRNA Silencing}

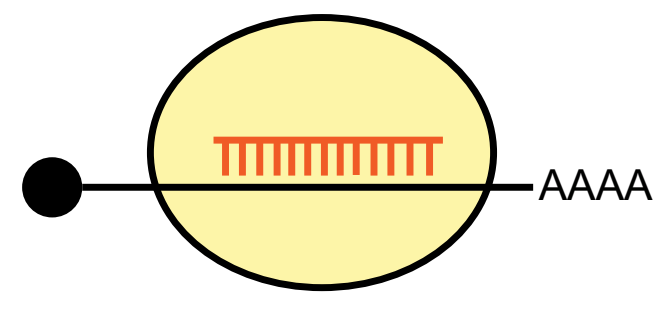




\section{Diagnostic Biomarkers}
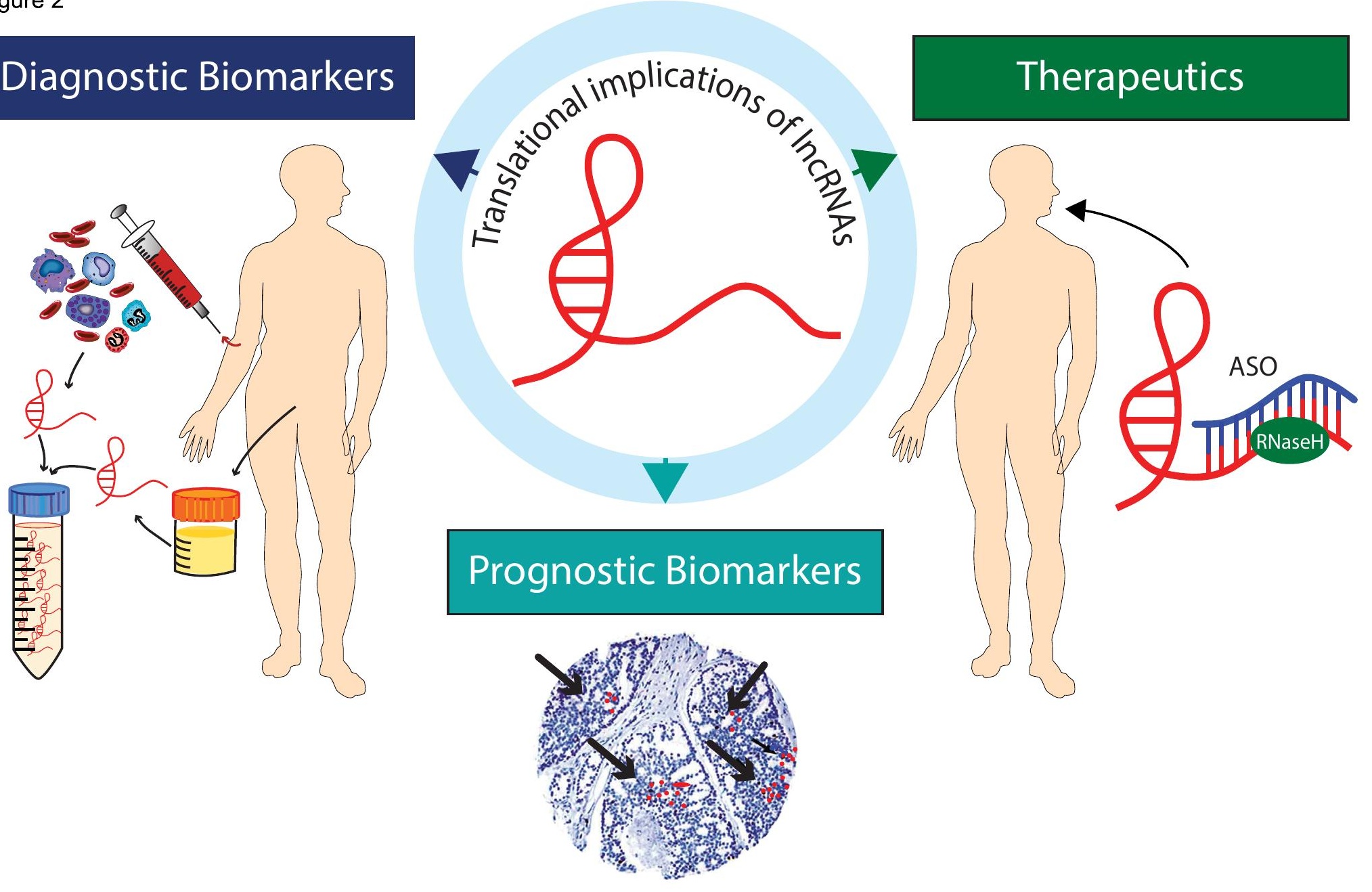

\section{Prognostic Biomarkers}




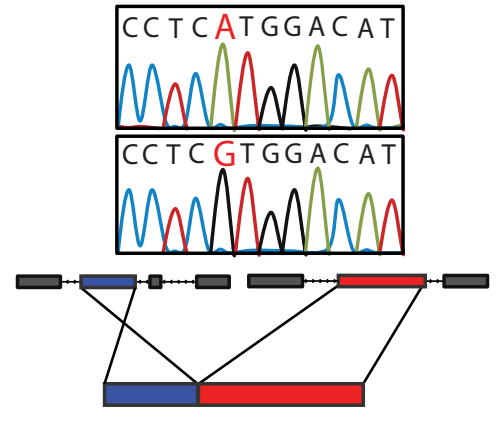

Transcript Variants

\section{Small Peptides}

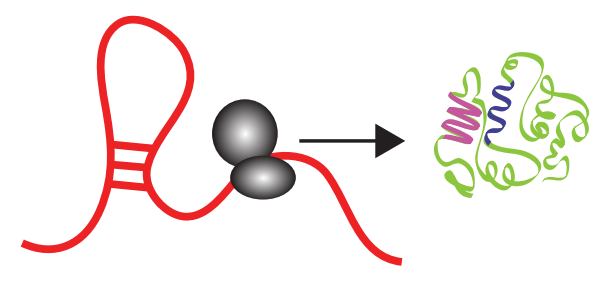

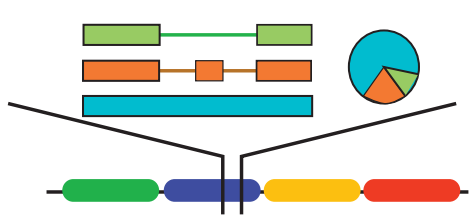

RNA-seq / Microarray
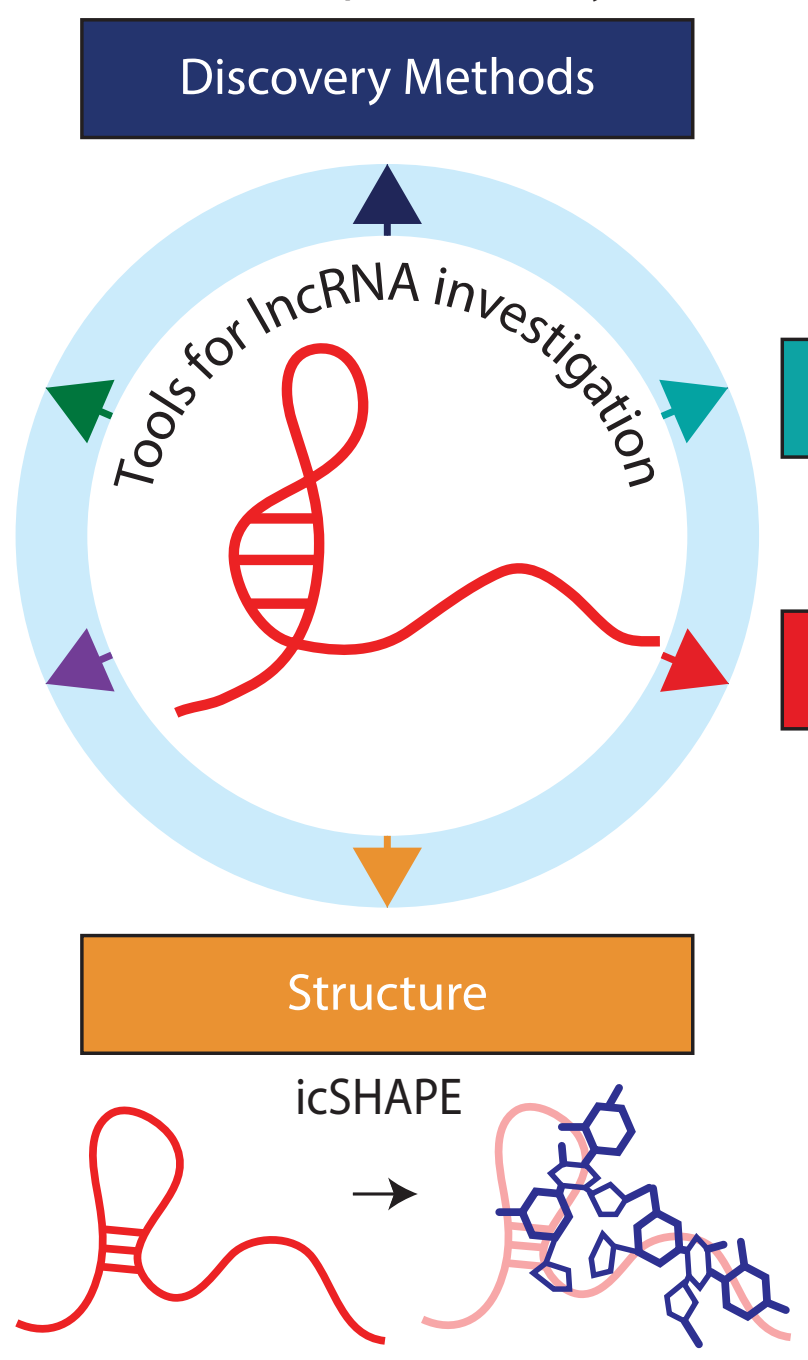

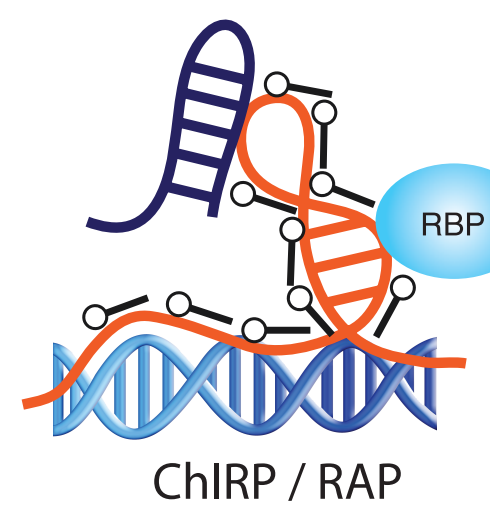

Interactome Analysis
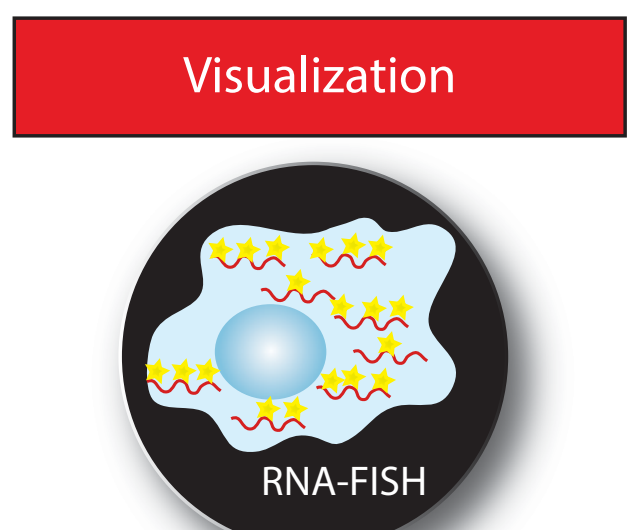
Table 1. Examples of long noncoding RNAs in cancer

\begin{tabular}{|c|c|c|c|c|}
\hline Name & Cancer Type(s) & $\begin{array}{c}\text { Tumor Suppressor/ } \\
\text { Oncogene }\end{array}$ & Mechanistic Theme(s) & Reference(s) \\
\hline $\begin{array}{l}\text { ANRIL (ANtisense noncoding RNA in the } \\
\text { INK4 Locus) }\end{array}$ & gastric & oncogene & $\begin{array}{l}\text { cell cycle regulation, epigenetic } \\
\text { complex, miRNA regulation }\end{array}$ & $14,34,85$ \\
\hline $\begin{array}{c}\text { BANCR (BRAF Activated NonCoding } \\
\text { RNA) }\end{array}$ & melanoma, NSCLC & oncogene, tumor suppressor & chemokine signaling, EMT & $99-100$ \\
\hline $\begin{array}{l}\text { BCAR4 (Breast Cancer Anti-estrogen } \\
\text { Resistance-4) } \\
\end{array}$ & breast, multiple & oncogene & Hedgehog signaling pathway & $90,104-105$ \\
\hline $\begin{array}{l}\text { CARLo-5 (Cancer-Associated Region } \\
\text { Long non-coding RNA-5) }\end{array}$ & $\begin{array}{l}\text { colorectal, gastric, NSCLC, } \\
\text { prostate }\end{array}$ & oncogene & apoptosis, cell cycle regulation, EMT & $65-67$ \\
\hline $\begin{array}{c}\text { CCAT1 (Colon Cancer Associated } \\
\text { Transcript 1) }\end{array}$ & colorectal & oncogene & MYC & 119 \\
\hline $\begin{array}{c}\text { CCAT2 (Colon Cancer Associated } \\
\text { Transcript 2) }\end{array}$ & $\begin{array}{l}\text { breast, colorectal, esophageal } \\
\text { squamous cell, NSCLC }\end{array}$ & oncogene & $\begin{array}{l}\text { chromosomal instability, MYC, Wnt } \\
\text { signaling pathway, }\end{array}$ & $92-95$ \\
\hline $\begin{array}{c}\text { CTBP1-AS (C-Terminal Binding Protein } 1 \\
\text { - AntiSense) }\end{array}$ & prostate & oncogene & hormone-regulated & 113 \\
\hline $\begin{array}{l}\text { DRAIC (Downregulated-RNA in } \\
\text { Androgen-Independent Cells) }\end{array}$ & multiple, prostate & tumor suppressor & hormone-regulated & 112 \\
\hline $\begin{array}{c}\text { FAL1 (Focally Amplified LncRNA on } \\
\text { chromosome 1) }\end{array}$ & multiple epithelial type, ovarian & oncogene & $\begin{array}{l}\text { cell cycle regulation, epigenetic } \\
\text { complex }\end{array}$ & 31 \\
\hline $\begin{array}{l}\text { gadd7 (growth-arrested DNA damage- } \\
\text { inducible IncRNA) }\end{array}$ & non-specific & tumor suppressor & $\begin{array}{l}\text { cell cycle regulation, DNA damage } \\
\text { response } \\
\end{array}$ & 68 \\
\hline $\begin{array}{c}\text { GAPLINC (Gastric Adenocarcinoma } \\
\text { Predictive Long Intergenic NonCoding } \\
\text { RNA) }\end{array}$ & gastric & oncogene & ceRNA & 84 \\
\hline GAS5 (Growth Arrest Specific 5) & $\begin{array}{l}\text { non-specific, mesothelioma, } \\
\text { prostate }\end{array}$ & tumor suppressor & apoptosis & $71-72,108$ \\
\hline $\mathrm{H} 19$ & $\begin{array}{l}\text { colorectal, gastric, glioma, } \\
\text { osteosarcoma, pancreatic }\end{array}$ & oncogene & miRNA interaction, signal transduction & $76-80,91$ \\
\hline $\begin{array}{c}\text { HOTAIR (HOX Transcript Antisense } \\
\text { Intergenic RNA) }\end{array}$ & $\begin{array}{c}\text { breast, colorectal, } \\
\text { hepatocellular, GIST }\end{array}$ & oncogene & epigenetic complex, miRNA regulation & $19-22$ \\
\hline $\begin{array}{l}\text { HOTTIP (HOXA Transcript at the distal } \\
\text { TIP) }\end{array}$ & hepatocellular & oncogene & epigenetic complex & $53-54$ \\
\hline $\begin{array}{l}\text { HULC (Hepatocellular Upregulated Long } \\
\text { nonCoding RNA) }\end{array}$ & hepatocellular & oncogene & ceRNA & $82,126-127$ \\
\hline $\begin{array}{c}\text { LED (LncRNA activator of Enhanced } \\
\text { Domains) }\end{array}$ & leukemia, non-specific & tumor suppressor & $\begin{array}{l}\text { cell cycle regulation, epigenetic } \\
\text { regulation } \\
\end{array}$ & 63 \\
\hline lincRNA-p21 & non-specific & tumor suppressor & $\begin{array}{l}\text { cell cycle regulation, epigenetic } \\
\text { regulation } \\
\end{array}$ & 15,59 \\
\hline $\begin{array}{c}\text { IncRNA-ATB (IncRNA-Activated by TGF- } \\
\beta)\end{array}$ & hepatocellular & oncogene & ceRNA, EMT, TGF- $\beta$ signaling & 83 \\
\hline $\begin{array}{c}\text { IncRNA-HEIH (IncRNA-High Expression In } \\
\text { HCC) }\end{array}$ & hepatocellular & oncogene & $\begin{array}{l}\text { cell cycle regulation, epigenetic } \\
\text { complex }\end{array}$ & 33 \\
\hline IncRNA-LET (Low Expression in Tumor) & $\begin{array}{l}\text { colorectal, hepatocellular, lung } \\
\text { squamous }\end{array}$ & tumor suppressor & hypoxia, metastasis & 17 \\
\hline IncTCF7 & hepatocellular & oncogene & $\begin{array}{l}\text { epigenetic complex, Wnt signaling } \\
\text { pathway }\end{array}$ & 42 \\
\hline $\begin{array}{l}\text { MALAT1 (Metastasis Associated Lung } \\
\text { Adenocarcinoma Transcript-1) }\end{array}$ & $\begin{array}{l}\text { endometrioid endometrial, } \\
\text { lung, renal cell }\end{array}$ & oncogene & $\begin{array}{l}\text { EMT, metastasis, Wnt signaling } \\
\text { pathway }\end{array}$ & $96-98,129-132$ \\
\hline MEG3 (Maternally Expressed 3) & $\begin{array}{c}\text { colorectal, gastric, } \\
\text { hepatocellular, meningioma, } \\
\text { NSCLC } \\
\end{array}$ & tumor suppressor & $\begin{array}{l}\text { DNA damage response, miRNA } \\
\text { interaction }\end{array}$ & $60-61$ \\
\hline MIR31HG & melanoma & tumor suppressor & cell cycle regulation, OIS & 64 \\
\hline $\begin{array}{l}\text { NBAT-1 (NeuroBlastoma Associated } \\
\text { Transcript-1) }\end{array}$ & neuroblastoma & tumor suppressor & epigenetic complex & 32 \\
\hline $\begin{array}{l}\text { NEAT1 (Nuclear Enriched Abundant } \\
\text { Transcript-1) }\end{array}$ & $\begin{array}{l}\text { breast, multiple solid type, } \\
\text { prostate }\end{array}$ & oncogene & $\begin{array}{l}\text { epigenetic regulation, hormone- } \\
\text { regulated, hypoxia }\end{array}$ & $106-107$ \\
\hline NKILA (NF-KappaB Interacting LncRNA) & breast & tumor suppressor & $\begin{array}{c}\text { inflammation in tumor } \\
\text { microenvironment, regulation of } \\
\text { signal transduction }\end{array}$ & 122 \\
\hline $\begin{array}{l}\text { PANDA (P21 associated NcRNA DNA } \\
\text { damage Activated) }\end{array}$ & non-specific, leukemia & tumor suppressor & $\begin{array}{l}\text { cell cycle regulation, DNA damage } \\
\text { response }\end{array}$ & 16,40 \\
\hline $\begin{array}{c}\text { PCAT-1 (Prostate Cancer Associated } \\
\text { Transcript 1) }\end{array}$ & prostate & oncogene & $\begin{array}{c}\text { miRNA like function, regulation of } \\
\text { DNA damage repair, repression of a } \\
\text { tumor suppressor }\end{array}$ & $69-70,86$ \\
\hline $\begin{array}{c}\text { PCAT29 (Prostate Cancer Associated } \\
\text { Transcript 29) } \\
\end{array}$ & prostate & tumor suppressor & hormone-regulated & $111-112$ \\
\hline PCGEM1 (prostate-specific transcript 1) & prostate & oncogene & hormone-regulated, MYC & $114-116,118$ \\
\hline $\begin{array}{l}\text { PRNCR1 (PRostate cancer associated } \\
\text { Non Coding RNA 1) }\end{array}$ & prostate & oncogene & hormone-regulated & $114-115$ \\
\hline PVT1 & colorectal & oncogene & MYC & 120 \\
\hline $\begin{array}{l}\text { SChLAP1 (Second Chromosome Locus } \\
\text { Associated with Prostate 1) }\end{array}$ & prostate & oncogene & epigenetic complex & $41,50-52$ \\
\hline $\begin{array}{c}\text { TARID (TCF21 Antisense RNA Inducing } \\
\text { Demethylation) }\end{array}$ & non-specific & tumor suppressor & $\begin{array}{c}\text { DNA demethylation, epigenetic } \\
\text { regulation }\end{array}$ & 23 \\
\hline TUG1 (Taurine UpreGulated 1) & $\begin{array}{c}\text { esophageal squamous cell, } \\
\text { NSCLC }\end{array}$ & oncogene & $\begin{array}{c}\text { DNA damage response, epigenetic } \\
\text { complex } \\
\end{array}$ & 35 \\
\hline XIST (X Inactive Specific Transcript) & breast, hematologic & tumor suppressor & epigenetic complex & 11,36 \\
\hline
\end{tabular}

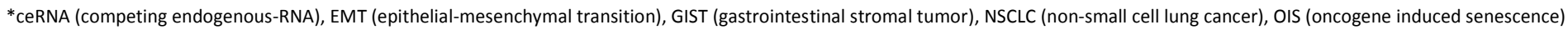


Table 2. Biomarker potential of long noncoding RNAs in cancer

\begin{tabular}{|c|c|c|c|c|}
\hline Name & Cancer Type(s) & Diagnostic/Prognostic & Blood/Tissue/Urine & Reference(s) \\
\hline $\begin{array}{l}\text { ANRIL (ANtisense noncoding RNA in the INK4 } \\
\text { Locus) }\end{array}$ & gastric & prognostic & tissue & 34 \\
\hline BANCR (BRAF Activated NonCoding RNA) & NSCLC & prognostic & tissue & 100 \\
\hline BCAR4 (Breast Cancer Anti-estrogen Resistance-4) & breast & prognostic & tissue & 90 \\
\hline $\begin{array}{l}\text { CARLo-5 (Cancer-Associated Region Long non- } \\
\text { coding RNA-5) }\end{array}$ & NSCLC & prognostic & tissue & 67 \\
\hline CCAT2 (Colon Cancer Associated Transcript 2) & breast & prognostic & tissue & 92 \\
\hline $\begin{array}{l}\text { DRAIC (Downregulated-RNA in Androgen- } \\
\text { Independent Cells) }\end{array}$ & multiple, prostate & prognostic & tissue & 112 \\
\hline FAL1 (Focally Amplified LncRNA on chromosome 1) & ovarian & prognostic & tissue & 31 \\
\hline $\begin{array}{l}\text { GAPLINC (Gastric Adenocarcinoma Predictive Long } \\
\text { Intergenic NonCoding RNA) }\end{array}$ & gastric & diagnostic, prognostic & tissue & 84 \\
\hline GAS5 (Growth Arrest Specific 5) & gastric & prognostic & tissue & 72 \\
\hline HOTAIR (HOX Transcript Antisense Intergenic RNA) & $\begin{array}{l}\text { breast, colorectal, GIST, } \\
\text { hepatocellular }\end{array}$ & prognostic & tissue & $19-22$ \\
\hline HOTTIP (HOXA Transcript at the distal TIP) & hepatocellular & prognostic & tissue & 53 \\
\hline $\begin{array}{l}\text { HULC (Hepatocellular Upregulated Long nonCoding } \\
\qquad \text { RNA) }\end{array}$ & hepatocellular, pancreatic & diagnostic, prognostic & blood, tissue & $126-127$ \\
\hline IncRNA-HEIH (IncRNA-High Expression In HCC) & hepatocellular & prognostic & tissue & 33 \\
\hline $\begin{array}{l}\text { MALAT1 (Metastasis Associated Lung } \\
\text { Adenocarcinoma Transcript-1) }\end{array}$ & $\begin{array}{l}\text { colorectal, glioma, prostate, } \\
\text { renal cell }\end{array}$ & diagnostic, prognostic & blood, tissue & $96,129-132$ \\
\hline MEG3 (Maternally Expressed 3) & NSCLC & prognostic & tissue & 61 \\
\hline NBAT-1 (NeuroBlastoma Associated Transcript-1) & neuroblastoma & prognostic & tissue & 32 \\
\hline NEAT1 (Nuclear Enriched Abundant Transcript-1) & prostate & prognostic & tissue & 107 \\
\hline NKILA (NF-KappaB Interacting LncRNA) & breast & prognostic & tissue & 122 \\
\hline PCA3 (Prostate Cancer Antigen 3) & prostate & diagnostic & urine & 128 \\
\hline PCAT29 (Prostate Cancer Associated Transcript 29) & prostate & prognostic & tissue & 111 \\
\hline $\begin{array}{l}\text { SChLAP1 (Second Chromosome Locus Associated } \\
\text { with the Prostate } 1 \text { ) }\end{array}$ & prostate & prognostic & tissue, urine & $41,50-52$ \\
\hline TUG1 (Taurine UpreGulated 1) & NSCLC & prognostic & tissue & 35 \\
\hline
\end{tabular}

* GIST (gastrointestinal stromal tumor), NSCLC (non-small cell lung cancer) 